\title{
A propósito de Rodrigo Saldarriaga Sanín (1950-2014) y su propuesta estética teatral en la ciudad de Medellín
}

DOI: $10.22395 /$ csye.v6n11a8

\section{Óscar Jairo González Hernández*}

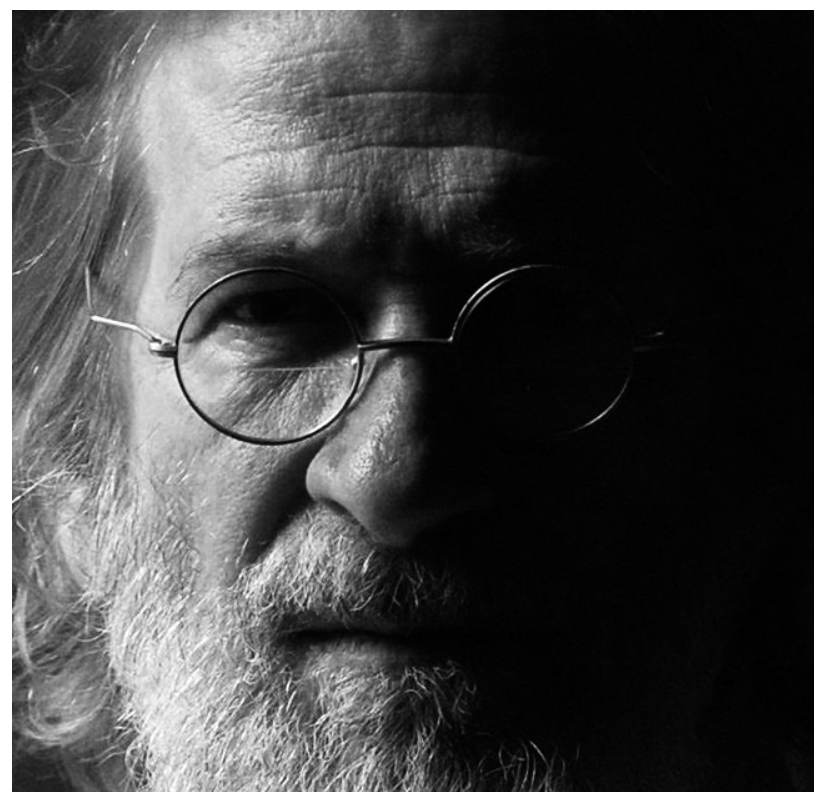

Rodrigo Saldarriaga

Y así será ${ }^{1}$

El transcurrir del tiempo biológico es veloz: cuarenta y cinco años en la vida de un hombre es la distancia entre su juventud y su vejez, entre el principio y el final. Ese mismo tiempo en la vida de una sociedad es el zigzagueo de los acontecimientos en un presente continuo, en donde las transformaciones son imperceptibles, y el tiempo del universo se debate entre la eternidad absoluta hacia su origen y hacia su fin.

Somos tan efímeros como una escena de teatro, como un personaje de teatro, como el atrezo del teatro.

\footnotetext{
* Licenciado en Filosofía y Letras de la Universidad Santo Tomás, magíster en Teoría de Historia del Arte de la Universidad de Antioquia. Profesor de la Facultad de Comunicación y Lenguajes Audiovisuales de la Universidad de Medellín. Correo electrónico: ojgonzalez@udem.edu.co

1 Tomado de Saldarriaga, Rodrigo (2013). Tercer timbre. Medellín. Medellín: Ediciones Camerino, pp. 167-168.
} 
La decisión de aquella noche en el Teatro Pablo Tobón desató la reacción en cadena a partir de una pequeña masa crítica de rebeldía, y convirtió mi vida en un canto de libertad, de disfrute y de profundas satisfacciones no exentas de angustias y dolores.
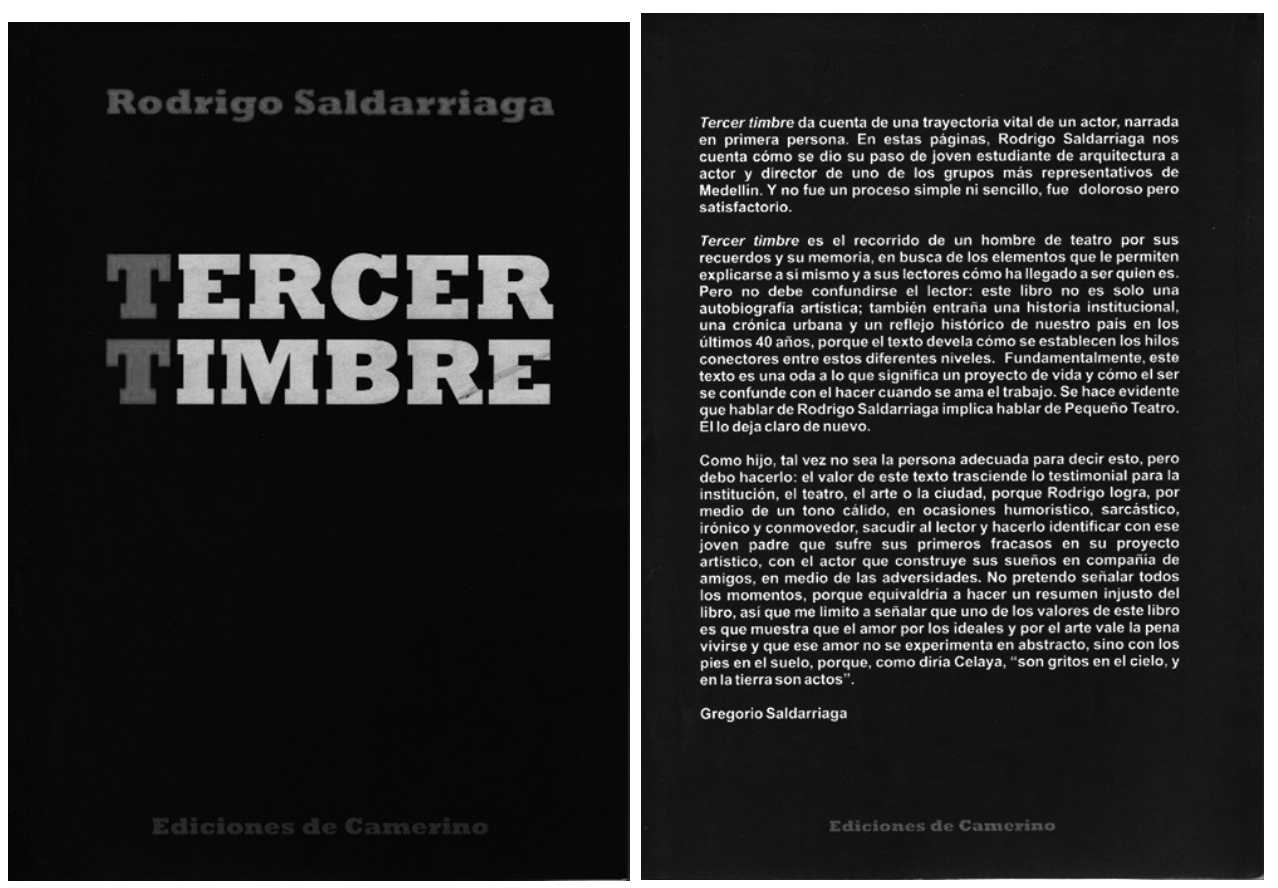

Carátula y contra-carátula de Tercer timbre de Rodrigo Saldarriaga

El montaje de cada una de las setenta o más obras que he enfrentado en estos años ha sido mi escuela, cada autor mi tutor y cada temporada una aventura. En el empírico aprendizaje de este oficio me tardé la vida entera, pero valió la pena. Me he gastado el tiempo que me fue dado en lo que me ha dictado mi corazón, sin seguir modas ni modelos, sin recibir órdenes, sin buscar recompensas de nadie.

El goce de un descubrimiento, el deleite de compartir todas las noches con el anónimo público, la satisfacción de levantar ladrillo a ladrillo el anhelado edificio para el teatro, la alegría de acompañar a los jóvenes de la Escuela en su aprendizaje del oficio, la tertulia interminable de las noches de cerveza y cigarrillo han hecho de mi vida en el teatro una certeza que me lleva a concluir que valió la pena huir del destino para encontrarme al final del tiempo con la satisfacción de un sueño.

Creo haberles sido fiel a mis principios, a mi partido y a mis muchas pasiones; haber buscado la Armonía, seguido con pasión el norte de la Utopía 
y disfrutado la vida. Por desgracia o por fortuna me tocó vivir en la época del neoliberalismo, la más triste de la humanidad: el arte y el humanismo apaleados y apabullados por la ideología del consumismo, por la cantinela de la Dama de Hierro y del vaquero impúdico del macartismo de "lo que no renta, no sobrevive". Los paradigmas del arte y la cultura, de la solidaridad, de la igualdad y la paz, hijos de las derrotas de las dos confrontaciones mundiales del siglo XX, fueron trocados por un nihilismo hirsuto, por un espectáculo vacío, por la industria del entretenimiento. Pero "se cantará también sobre los tiempos sombríos" y el teatro, tan parecido a la vida misma, brillará una vez más como lo ha hecho tantas veces, para de nuevo maravillarnos con sus poetas y conmovernos con sus intérpretes.

Los nietos de mi nieto disfrutarán nuevamente con Esquilo, con Shakespeare, con Strindberg y con Brecht, y el teatro volverá a ser el listón más alto del pensamiento como lo ha sido siempre. Habrán pasados los oscuros días de la ignorancia, de los pretenciosos necromantes de la "carne de perro" y de los desesperados desencantados del pensamiento.

Y yo estaré ahí, porque al cerrar los ojos el mundo no desaparecerá. 


\section{Rodrigo Saldarriaga: en perspectiva caballera}

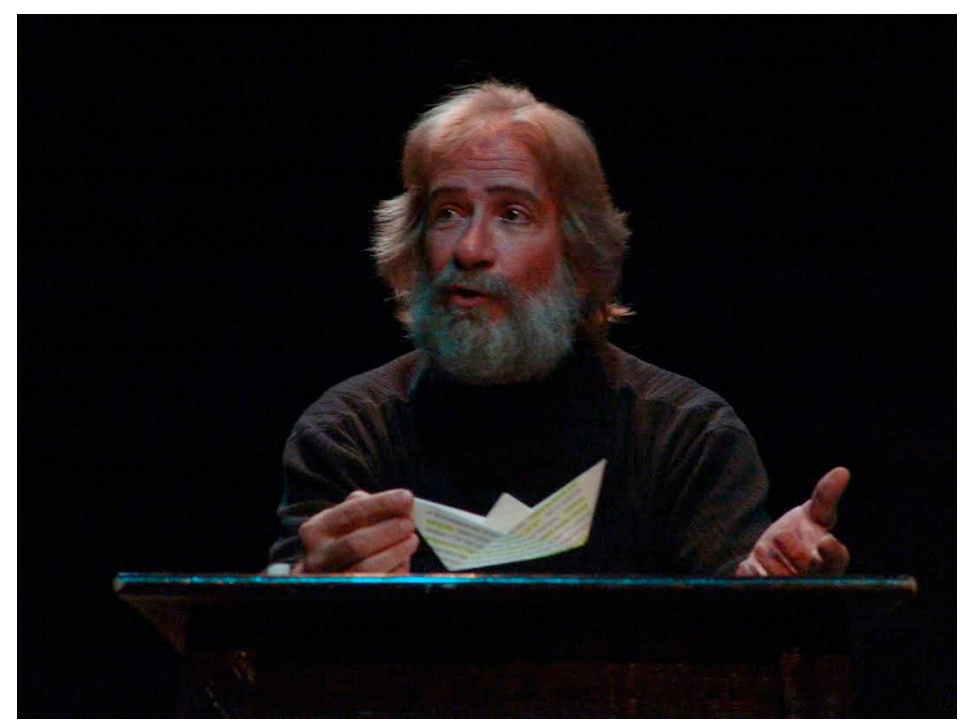

Rodrigo Saldarriaga

\section{Primer manifiesto}

Cuando hacemos arte, lo hacemos porque hemos decidido hacerlo. Y es una condición de nuestro carácter cuando decidimos que el arte sea observado y tratado por uno mismo desde el teatro. Medio para buscar la resolución teatral de mis tentativas y mis dudas, o, de exhibir o mostrar mi verdad, desde una conciencia crítica y sin medida. Tiendo a la inestabilidad estable del teatro. Y me domino en mi instinto o formo y construyó mi estética revolucionaria desde allí. Y ello sin que no medie la crítica. El teatro ya de por sí propone de la vida y sobre la vida una visión crítica y no consecuente e inclusive de cierta tendencia hacia la intolerancia estética y constructiva o destructiva. No es para ser dominado o intervenido por otro, sino para hacer lo que se quiere. En esa intencionalidad, entonces se necesita de la historia teatral, de una tradición teatral en la que apoyarse y estructurar su proyecto. Y desde ello, desde esa membrana y sustancia, RODRIGO SALDARRIAGA propuso, realizó y mostró su teatro, tal y como lo decía y sostenía (en lo insostenible) en 1989, al llevar (y llevarse) a escena La venganza de los huérfanos. El mundo griego tiene una extraña fascinación y ha ejercido una influencia en nuestra cultura; su filosofía, su visión cosmogónica, su teatro están presentes día a día en todo nuestro mundo contemporáneo, en nuestros conflictos y en nuestra vida. Tomar los mitos, las leyendas, los dioses, 
los héroes griegos y traerlos al presente ha sido una constante en la historia del teatro. Shakespeare, Anouilh, Cocteau, Brecht, Piñeres, y otros han creado obras partiendo del mundo griego, un mundo que permite una constante reflexión.

\section{Segundo manifiesto}

Cuando RODRIGO SALDARRIAGA entonces exhibía su propuesta desde su necesidad sensorial y de la percepción teórica e histórica, entonces era necesaria la crítica. La contracrítica. La provocación de lo contrario. Y la exhibición del contradictor. Es inherente al teatro cuando se exhibe. Exhibirse no es mostrarse, desde una estructura teatral. Y exhibirse teatralmente, desde unos principios y posiciones estéticas, conlleva la crítica. Y suscita la contradicción. Provoca el caos. Trae la perturbación e indica la temperatura de la crisis. Y el artista no busca la adhesión. Ni se exime de la crítica. No intenta ser exonerado ni condenado, porque lo esencial es exhibir lo que hace. No dudar en hacerlo. Causar irritación o risa, desde la conciencia de la teoría de la causalidad aristotélica. Tiene la temperatura para hacerlo, porque tiene conciencia de lo que lleva a la escena y la intención metódica de lo que realiza allí y se desarrolla después, en medio de lo que Berkeley llamaba barrer del escenario del mundo todo lo que es real y sustancial en la naturaleza. Aquí diríamos: en el teatro. Y se es por ello irreverente. Esencia de lo irreverente en la forma de propiciar nuevos elementos al teatro, desde mi visión e intención teatral. Hay que hacer maniobras tendenciales. Y él las hacía, porque se daba la libertad para hacerlo. Concibiendo pues, que la libertad da el poder, y el poder da la libertad, cuando es uno mismo que no teme abordarse ni abarcarse desde esa relación problemática e irresoluble: libertad y poder. Pero el proyecto nuevo lo debe incrustar, desde la revolución sensible y crítica, que tienda a transformar la realidad. E instalar una nueva, desde el teatro. Por eso en 2001, al llevar a escena el Wöyzeckde Büchner, indicó el sentido de esa tentativa con lucidez dramática: Büchner llega en un momento especial para mi carrera. Cuando me he desprendido de toda pretensión de director escénico y cuando a fuerza de montajes (más de 50) comprendí que el único papel del director es el de primer espectador. Pero para llegar a jugar este papel se requiere de un equipo de actores maduros que estén dispuestos a indagar en sus más recónditos pliegues de la memoria y a entregar con un lenguaje depurado la profunda reflexión que implica abordar un texto tan profundo como este de Büchner. Con Woyzeck-Büchner no pretendo decir nada, no pretendo ejemplarizar, no quiero que se mire el producto como un extraño espécimen, no aspiro ni al aplauso ni al rechazo, solo quiero exponerme en el teatro a mis más profundas creencias, a la búsqueda de un lenguaje que me empariente con la verdad y me haga huir de la mediocridad. 


\section{Tercer manifiesto}

Para Octave Mannoni, el teatro tiene otra escena (La otra escena) que sería, la que es básico buscar y tener, formar y estructurar para poder sentir y examinar, desde nosotros mismos, aquello que se nos exhibe, para poder tener los elementos de crítica que nos llevan a mayor densidad teatral de la excitación de los sentidos y de la conciencia indeleble e inalienable, sobre y en relación con aquello que no deseamos ser ni hacer en nuestro teatro. Nos formamos para disentir o no. Y entonces desde allí, haré intervenir, teatralmente, a quienes sintieron y tuvieron, y tienen todavía, relaciones con los principios teatrales de RODRIGO SALDARRIAGA, desde una perspectiva y otra, desde una necesidad esencial o inesencial y desde una condición estética trascendente o intrascendente, en y desde donde cada uno de ellos han sabido medir al hilo de sus intensidades y extrañamiento de quien ya no está entre ellos y que estará de otra manera de hoy en adelante. 


\section{Sobre y alrededor del dramaturgo, del actor y director teatral Rodrigo Saldarriaga (1950-2014)}

\section{Pequeño Teatro}

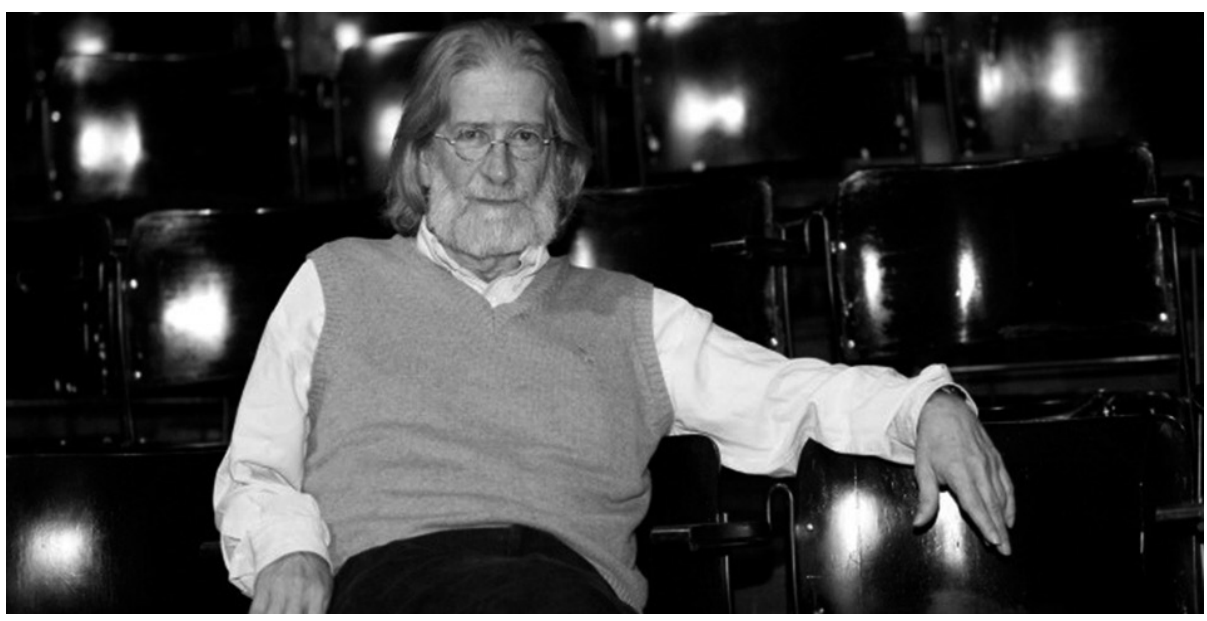

Rodrigo Saldarriaga

Entrevistas realizadas por Óscar Jairo González Hernández Profesor Facultad de Comunicación. Comunicación y Lenguajes Audiovisuales. Universidad de Medellín

1. ¿En la medida de su conocimiento, de experiencia y de su percepción teatral, cómo consideró y sintió la propuesta teatral de Rodrigo Saldarriaga y qué causó en usted y qué proyectó? (Sensitiva).

2. Cada quien tiene la libertad de adherirse o disentir críticamente de una estética teatral, cualquiera sea ella. ¿Podría decirnos hoy, antes y después de la muerte de Rodrigo Saldarriaga, en qué consistía para usted esa adhesión o disentimiento estético? (Crítica)

3. ¿Considera que Rodrigo Saldarriaga, propuso, desarrolló y fortaleció desde su vida como hombre del y para el teatro, una visión nueva o no del teatro y por qué? (Historia). 


\section{Victoria Valencia \\ La Mosca Negra Teatro}

1. En mi memoria habita un hombre limpio, ético, honesto, refinado, sobrio, y así construyó su obra, así la viví y la experimenté sobre el escenario. Es mi recuerdo. Un hombre hermoso, generoso, delicado. Una voluntad de hierro. Un profundo amor por sus actores, por sus actrices. Y todo esto se proyecta, se proyectó siempre en el escenario, en su obra.

¿Qué proyectó en mí? La que soy. Esta que permanece aquí, con un escenario incrustado en el corazón, arriesgando una dramaturgia, edificando un paisaje, tantas veces íngrima, pero invencible.

Eso hizo Rodrigo de mí, una apasionada de mi oficio, una guerrera en la libertad.

2. Lo que me desgarra, lo que me perturba, lo que me conmueve es a lo que me adhiero estéticamente, por naturaleza. Antes y ahora. Y mañana también.

3. Su arte es una consecuencia de su carácter, de sus ideas, de su conocimiento. $\mathrm{El}$ arte reúne los tiempos, los revuelve, los sobrepone en el escenario. Pasado, presente, futuro. Rodrigo es un artista y contiene todos los tiempos. "El arte es primordialmente infinito", dice Egon Schiele

Rodrigo nos enseñó sobre la voluntad, sobre la libertad, escupió a los burócratas, a los infames, a los mezquinos, eso lo han hecho antes y espero lo podamos seguir haciendo durante.

A mí me tocó una época deliciosa en el Pequeño Teatro, donde se aventuró con obras como Signos de la ciudad y El brillador de metal (una de las obras más profundas y conmovedoras que he visto, montada por el Pequeño Teatro y dirigida por él), de autores alemanes contemporáneos, que se apartaban de todos los cánones y convenciones de montaje teatral, eran obras arriesgadas y él, Rodrigo, las montó, con su visión, que vuelvo y digo, contiene todos los tiempos. Su visión, en últimas, es la visión del Artista.

\section{Farley Velásquez}

\section{Teatro La Hora 25}

1. Me recuerdo muchas veces entrando a la casa del Pequeño Teatro, con mi cabello a los hombros y mi piel sensitiva sentía que entraba a un bosque sagrado. Los actores vestidos de negro, entre ellos Omaira Rodríguez, bajaban por la Avenida Oriental, cada noche después de funciones y ensayos, impregnados del amor incondicional a su pequeño teatro que era grande en su corazón. En la sala pequeña de este templo vi innumerables representaciones, clásicas y contemporáneas, esta sala es un libro de secretos, abierto 
a los espectadores. Es el espacio del individuo que enfrenta y cuestiona el colectivo, el pensamiento masificado; debajo de un reflector aparecían los personajes soñados por su director e interpretados por los incontables actores que pisan sus tablas. De él recuerdo que era como un personaje medieval, un pirata de barba roja, cargado de ideología que saqueaba los barcos cargados de injusticias y corrupción política que zarpan cada día de los puertos de villanos que gobiernan este país. La defensa potente de su ideología, su amor por el comunismo y su capacidad de llamarse ateo, en la tierra donde los dioses nos los inventan los poderosos. Su fuerza constante y segura contra todos los obstáculos y los desafíos que enfrentamos los hombres para poder abrir una sala de teatro y mantenerla a flote bajo los huracanes, infortunios y dolores propios de la creación. Recuerdo su pasión intacta, hasta la última vez que lo vi, que sin desprenderse de un cigarrillo, reía a carcajadas y su potente voz resonaba como un personaje medieval, como un Rey Lear que decidió repartir sus conocimientos, dispuesto a vivir en la intemperie, si ese era el precio por dar la vida por lo que se piensa y se ama.

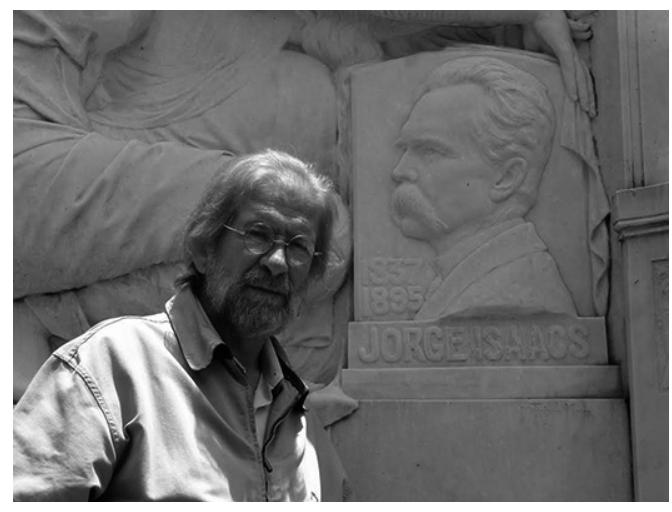

Rodrigo Saldarriaga

No dudo en expresar que ver su teatro me dio las fuerzas suficientes para abandonar la familia, un trabajo en alguna empresa y viajar a Ítaca para poder dedicarme el resto de la existencia a las artes escénicas, en esta ciudad, que él padeció, enfrentó, discriminado de los festivales de teatro que se hacen en Colombia, criticado por sus colegas y cuestionado por su busca de una política de izquierda que algún día desalojara a los eternos hombres que se aferran al poder político y social. Algunas noches compartimos algunos vinos, con algunos tabacos y hablamos de Shakespeare; era un placer escucharlo, aun en su despotismo y radicalidad que lo caracterizaron, hablar de Hamlet y Ofelia; se apasionaba de tal manera que seguiría hablando hasta el amanecer, así uno ya se hubiera ido, y él quizá terminaba hablando solo, bueno consigo mismo, al final entendía la soledad de los hombres verdaderos 
del teatro, pues él sabía que la muerte está en el resquicio de cualquier puerta, o al final de cada representación de teatro. Pues la vida es un telón que se abre y que se cierra.

Rodrigo se instaló en el corazón que late el teatro en Medellín; su posición, su amor casi de niño arrogante y poderoso que defiende su idea teatral frente a las espadas azarosas en las manos de los opositores, la defensa eterna del teatro que amaba y transmitía sin dudar jamás que el teatro debía estar al alcance de la masa enardecida y que un teatro podría tener la misma cantidad de seres humanos que llenan los estadios; pensó en su teatro inmenso, lleno de gente que podía vibrar bajo sus creaciones y apuestas teatrales. De él aprendí a no desfallecer y a hacer teatro, aunque la muerte nos invada nuestro interior y a pesar de que estamos de paso y que su legado queda para los hombres y mujeres que hacemos teatro y que nuestro destino es morir en las tablas defendiendo nuestro poema, aunque el reflector sea nuestro sol y el escenario la tumba, pues hasta el fin de los tiempos su teatro vibrará entre humos, tangos y poemas de Porfirio Barba Jacob.

2. El camino es infinito para la interpretación del teatro, la potencia de un grupo de creadores reside en su experiencia teatral, el resultado escénico es un proceso constante, cambiable, doloroso, repetitivo; son caminos conocidos solo por quien los recorre, es el resultado de cómo se observa lo que te rodea, qué situaciones dolorosas y bellas te cicatrizan el espíritu; ahora aprecio el teatro con otras percepciones, es el teatro del otro y lo potente de una relación de un artista con otro es que yo sufro el mío, y no importa si coincidimos o no, es la mirada diversa de lo humano, pues cualquier ser humano visto de cerca no es normal, cualquier cosa que hagamos en el teatro es una nimiedad frente a la crueldad o belleza que percibamos en el infinito cosmos de la puesta en escena, lo sencillo, lo gran elocuente, el amor, la guerra lo decible, lo indecible, al arte es Barroco, y si un creador atormentado por la existencia trata de sobrevivir cada día enfrentado la bestia humana, encuentra las letras de sangre que escriben su teatro.

Es importante que el otro me hable desde su teatro, porque es el teatro que yo no encuentro ni percibo en el mío, lo potente del teatro de Rodrigo era ver sus resoluciones escénicas, su pasión intacta y poderosa, vencer la muerte, abrir la sala cada día, no solo una, dos y llenarlas de personajes que nos interpretan y nos piensan y nos ayudan a soportar nuevos días; no es importante para mí disentir críticamente de una estética teatral; ahora me conmueven ver personas como este creador que se atrevió a encontrarse con los grandes pensadores del teatro y se los regaló a los espectadores por 
unos sinceros aplausos. Su teatro hace grande al mío en el sentido de que cada uno escribe su historia teatral y lucha por la libertad de su propia y única perversidad estética que lo hace grande en su teatro. Rodrigo elaboró su propio teatro. Y eso lo hizo encontrar su voz, tan necesaria en muchos hombres de teatro actuales, hombres cuya voz es el sonido estridente, falso de las monedas de sus bolsillos vacíos.

3. El teatro existe en la representación. Su legado es más potente en el sentido que lo dejó en sus actores, para que puedan, cada uno, encontrar su teatro en su interior. Uno no hace el teatro de otro, hace su teatro. El teatro es efímero, nace y muere en la representación; quedan los muros del templo teatral, los libros de dramaturgia. Quedan escritos sobre las experiencias y las resoluciones escénicas, quedan hombres y mujeres con una voz interior; el duende maravilloso que nos ayuda a construir el teatro, que podamos enfrentar el espacio vacío, la constancia, algunos vestuarios usados, fotografías, memoria teatral, es eso lo que tenemos que recoger de Rodrigo: su vitalidad, su energía teatral, su espiritualidad, pues el camino es largo e infinito y se necesita un relevo poderoso, que encuentre su propia voz, utilizando la fuerza que nos deja la ausencia del que se va, el amor del ausente, la capacidad para abrir una sala en Medellín y tenerla funcionando, pues las resistencias son vitales para los creadores; su visión, para mí es el recuerdo, que hace memoria, es llevar su teatro como una bandera para los que vienen, no dejarse vencer del hastío, porque él, como muchos creadores, luchó por el teatro de este país. País que paga muy mal si se hace un teatro que lo cuestione, que lo desnude, que lo critique, que se le oponga, y quizá Rodrigo es esa visión que nos dirá siempre que hay que continuar,

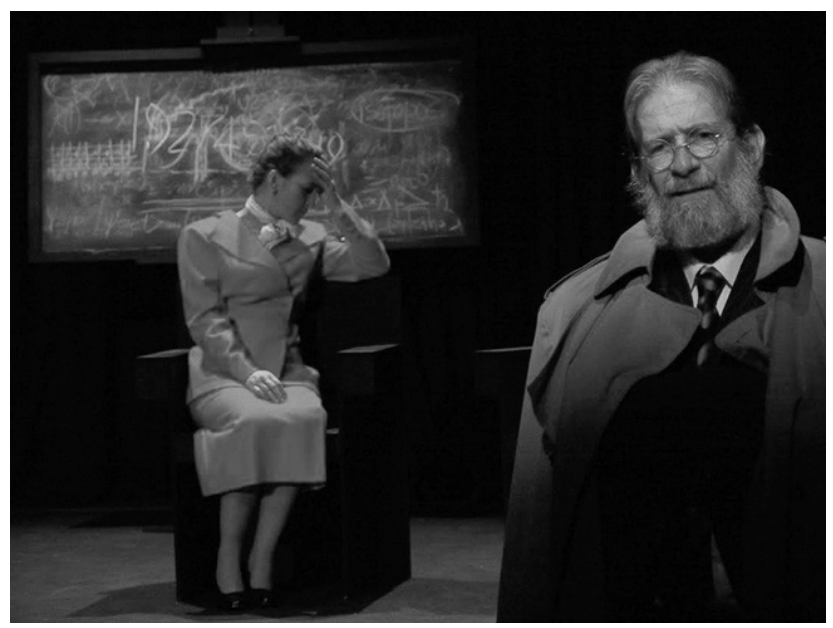

Rodrigo Saldarriaga y la representación de la obra 
que la muerte existe, pero que la idea se perpetúa, que es maravilloso irse del mundo sonriendo, huyendo de la muerte trágica en un hospital, que los hombres de teatro somos recibidos por Caronte, y que debemos continuar haciendo teatro por lo que nos dicen los maestros cuando se van. De Rodrigo tengo unos abrazos, algunas noches de teatro, al Rey Lear, que el teatro de William Shakespeare era alcanzable para los hombres de Medellín, a sus actores abrazos eternos y que el potencial poderoso de este hombre quede por siempre en los hombres que amamos por siempre el teatro.

\section{Felipe Caicedo}

\section{Anamnésico Teatro}

1. Solo conocí a Rodrigo Saldarriaga a través de sus obras y sus personajes (también a través de las vallas publicitarias de su última campaña). Lo escuché en varias ocasiones hablar sobre el proyecto teatral de Pequeño Teatro de Medellín, y tuve la oportunidad de leer la entrevista que publicará ATEATRO en su N. ${ }^{\circ} 17$ en 2010. Estas minucias me bastaron para saber que era un hombre recto y firme en sus posturas, de horizontes claros y de un profundo conocimiento del teatro del mundo. La estética de su teatro, de su manera de abordar el acontecimiento escénico dista mucho de lo que busco ver y hacer en el teatro. Últimamente dediqué buena parte de mi tiempo ocioso a ver las obras que se presentaban en las dos salas de Pequeño Teatro de Medellín, pues me propuse quitarme el velo local y sobre todo impuesto por la pose de teatrero esnob de que: El Pequeño Teatro es malo. Cuando comencé a ir (pues aún antes de conocerlos yo ya repetía como muchos la frase que cito anteriormente) descubrí que detrás de aquellos clásicos existía un ser similar al Banquero anarquista que nos retrata Pessoa. Descubrí en EL PEQUEÑO TEATRO un modelo de anarquismo del que yo quería sustraer muchas cosas: no asociarse. Por ejemplo, no vincularse con el Estado, no recibir un peso de nadie, como diría Rodrigo en muchas ocasiones.

2. El PEQUEÑO TEATRO de Medellín ha montado a muchos de los padres del teatro en el mundo, han montado todo lo que un estudiante de teatro debe conocer para hacerse teatrero. En pequeño teatro se montan los textos, se interpretan, se dicen. Y se dicen para el pueblo, pues desde sus inicios, Pequeño Teatro se concibió como un teatro para todos. De ahí que el aporte voluntario sea la mayor contribución a este objetivo dentro de la escena local. En esto está mi mayor disentimiento, crear para la masa. No confío mis adherencias (y el Pequeño Teatro no es el único ejemplo en esta ciudad teatral) a un teatro que se preocupe demasiado por el público masivo, que desmenuce su estética escénica para que pueda ser deglutida por todos. Un teatro en donde el espectador es una cifra me preocupa completamente. Lejos 
de esta distancia hacía su hecho escénico, no dejo de reconocer la búsqueda terca y beligerante de esta tropa de enamorados de lo que hacen. Exista o no adherencia con lo que quiera en mi teatro, valoro y siempre estaré adherido a los proyectos que se hagan al margen de cualquier condicionamiento, a proyectos libres e inútiles en sus concepciones puras, y siento que en el Pequeño Teatro se alberga una semilla de estas dos palabras.

3. Propuso una visión, nueva para el momento en que la propuso, y no nueva para el momento actual. Desde el mismo nombre del grupo, Pequeño Teatro es una apuesta por la recuperación de lo clásico sobre la escena local. Desde un Eurípides, pasando por un Moliere, hasta llegar a un Tomás Carrasquilla, este grupo es un baúl del recuerdo en donde uno puede meter la mano y sacar de su repertorio un autor a su antojo. Sorprende y pareciera inabarcable el repertorio de talla universal con que cuentan. Muchas de sus obras pueden incluirse en el repertorio clásico del teatro de Medellín, tal es el caso de "En la diestra de Dios Padre" y "Madre Coraje". Propuso, desarrolló y fortaleció un teatro que aboga por las formas clásicas, desde los autores hasta la manera de abordar la escena, siempre puesta bajo los cánones más tradicionales.

\section{Ángela María Chaverra Brand \\ Colectivo artístico El Cuerpo Habla}

Yo no fui una asidua visitante del Pequeño Teatro. Primero porque no me gustaba esa parte del aporte voluntario. Sentía que ello iba contra la formación de un público y con la necesidad de pagar por la entrada a teatro, con la dignidad que exige la escena, pero el Pequeño Teatro tenía muy clara esa manera de hacer teatro y les funcionó. Hasta muchos grupos adoptaron ese sistema.

Segundo, la escena se me hacía muy pesada; sentía que a la dirección teatral de Rodrigo le hacía falta frescura, era muy acartonada, puesta la fuerza en el texto. Sin embargo, rescato la integridad de sus actores, el mantener por tanto tiempo una apuesta por su teatro. La capacidad de sus actores, su entrega, su histrionismo. Una de las obras que me impactó fue Esperando a Godot. Siento que fue una de las puestas en escena que más me atrajo del trabajo de Rodrigo.

Nunca creo que tuve un real acercamiento con él y en cambio diferíamos en la manera de ver el mundo. No fuimos amigos, pero admiraba su capacidad de gestión, el lograr el sueño de tener un espacio tan importante para la escena, el hecho de que, aunque tuviera muchos opositores, siempre estuvo en su lugar y supo sostener su sueño. Eso lo hace grande.

Pienso que nunca pude encontrarme con su manera de hacer teatro y de pensar el mundo. A pesar de ser su adherencia al Polo, nunca tuve una simpatía 
por su candidatura para la gobernación. Simplemente no me parecía, no creía que una persona que se opuso con tanta vehemencia a ciertas prácticas teatrales más contemporáneas, y criticó a tantas personas, fuera abierta a la diferencia, y esto me hacía no compartir sus ideales políticos.

Siempre me pareció un ser muy elegante, muy bello físicamente, un poco arrogante, de unos modales impecables y una cultura vasta. Yo sentía cierta imponencia cuando compartimos alguna que otra palabra, pero me imagino que también era la incapacidad que tenía yo, para debatirlo abiertamente.

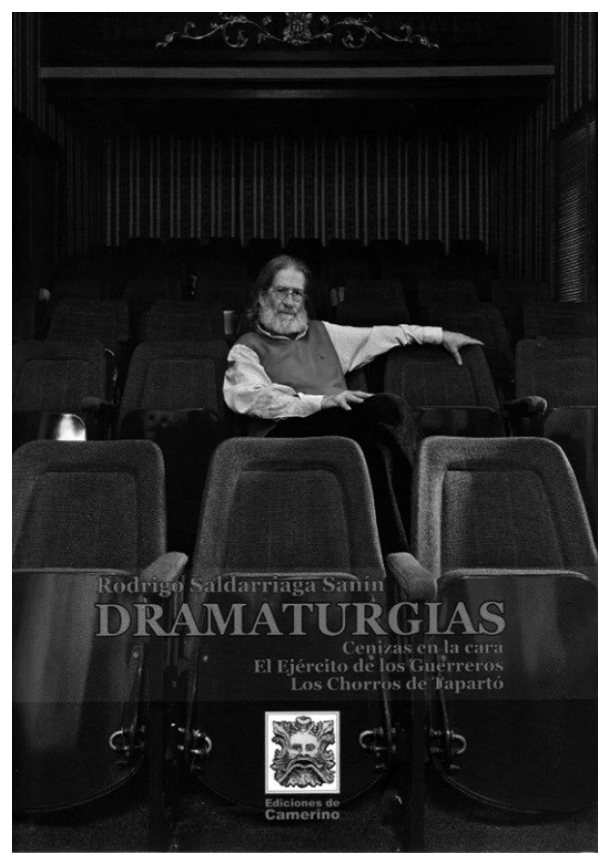

Rodrigo Saldarriaga y su obra Dramaturgias

En los montajes me parecía que los actores eran muy rígidos, que faltaba quebrar esa idea de un teatro tan serio y clásico; sentía que los gestos eran demasiado obvios, que la imagen permitía una lectura muy lineal, y que por ello faltaba hacer más énfasis en la construcción de una dramaturgia del actor. A pesar de montar textos políticos sentía que había una lejanía con el público, pero que de todas maneras se hizo un nombre y un lugar en la escena de Medellín. Montó escuela, realizó innumerables puestas en escena, fue crítico con el sistema. Seguramente muchos sentirán de manera diferente su forma de hacer teatro, pero es lo más honesto que puedo decir.

Pienso que Rodrigo se forjó un lugar en la historia del teatro de Medellín, por su empeño, por su fortaleza, por ser crítico con el medio y por reivindicar una 
manera de hacer teatro. Mantener una perspectiva del teatro; ser fiel a lo que se piensa y cree es también una manera de resistencia frente a los embates de la Contemporaneidad.

Construyó con mucha tenacidad uno de los espacios más bellos para el teatro, una sala muy versátil y tuvo amigos muy sinceros, lo digo porque se puede ver cómo, muchos de los actores que iniciaron con él, se quedaron y compartieron los triunfos y me imagino que los fracasos.

Yo realmente no puedo hablar mucho de él, fue siempre un trato lejano, vi algunas, no muchas de sus obras, sobre todo en la década de los 90. Para el nuevo siglo, mis idas al Pequeño Teatro se redujeron considerablemente.

\section{Mikhail Hernández}

1. El Pequeño Teatro para mí fue uno de los primeros referentes del teatro en mi vida; si bien lo fueron también Hora 25, Matacandelas y Teatro Oficina Central de los Sueños, sería el Pequeño Teatro uno de los espacios en los que pude apreciar más obras debido a la facilidad que tenía para acceder a su teatro. De esta experiencia puedo resaltar que debido a la diversidad de las puestas en escenas logré acercarme a varios autores importantes de la historia de la literatura y del teatro y, además, comenzar a tomar mis propios criterios sobre las puestas en escena y estética que tenía el pequeño teatro frente a los otros grupos profesionales de teatro de la ciudad, es decir, me dio la oportunidad de hacer un ejercicio continuo del quehacer teatral.

2. Siempre hubo y habrá admiración por el trabajo que desarrolló y fortaleció Rodrigo Saldarriaga con Pequeño Teatro; creo que todo hombre que entrega su vida a este arte tiene un granito de arena, como se dice, importante para la historia de las artes representativas o artes vivas, es decir, Rodrigo Saldarriaga y todos los integrantes que hoy están y los que estuvieron en este barco que navega los mares escénicos tienen una visión única y particular que generó en vida el maestro Rodrigo Saldarriaga, una bandera estética que tanto con seguidores como detractores dejó en lo alto. Hizo historia, dejó memoria y toda esa energía se escenifica, toma vida al subir el telón del Pequeño Teatro.

3. Como dije inicialmente El Pequeño Teatro con su política de "entrada libre con aporte voluntario" me dio la oportunidad de ejercer una continua contemplación del arte escénico como ellos lo concebían y con ello una reflexión y crítica de su estética frente a la de los demás grupos que iba conociendo paralelamente; en esa exploración fui tomando partido por algunas estéticas particulares que tenían otros grupos y comenzaba a discernir frente a una 
actuación que, sin duda, era muy buena pero que no transmitía en mí lo que lograban otros directores, es decir, más allá de las puestas en escena, de las dramaturgias que tenía el Pequeño Teatro, la brecha con la que comenzaba a encontrarme en su teatro era la actuación que tenía su escuela. Dejé de tener esa comunión que debe producirse en el ritus entre el espectador y los actores que están en escena... tal vez, en cierta medida haya influido tener que compartir con públicos que no estaban interesados en conectarse sinceramente con el teatro, con su magia, sino que iban como una moda intelectual de estar en un lugar más que visitar de la ciudad y que ese fácil acceso que me dio a mí inicialmente a conocer su obra fue unos de los que luego se convirtió en el enemigo para sentirme cómodo Y compartir de ese ritus.

\section{Andrés Moure}

\section{"Tuve siempre con Rodrigo un encuentro de vida muy importante..."}

1. Creo que fue coherente con lo que pensaba y creía era el arte teatral. La palabra hablada fue una de sus aficiones y nos exigía mucho en este sentido. Su visión del actor como un ser sensible y primer creador del teatro fue de vital importancia en mi crecimiento actoral. Tenía una idea totalizadora del hecho teatral; su cuasi profesión de arquitecto le permitía plantear muy claramente la espacialidad creando para el actor un espacio sugerente.

2. Todo creador, de alguna manera, tiene un sello personal. En ese sentido Rodrigo tuvo un sello que, aunque muchos tildaban de clásico, hizo de él y su trabajo un referente para el teatro actual. La elección de las obras que montó estaba profundamente ligada a su posición humanística y política y por eso creo que le habló a la sociedad. Con el tiempo su trabajo será valorado y su posición siempre honesta tendrá su lugar.

3. Tuve con Rodrigo siempre un encuentro de vida muy importante, fue como mi padre artístico. Estuve de acuerdo con sus planteamientos estéticos y creativos. Su aporte en la formación de los actores fue de vital importancia para la Escuela y siempre tuvo espacio para la discusión acerca del arte. La búsqueda de un espacio limpio y sugerente fue uno de sus estandartes. Creía en el trabajo del actor y actuaba como un guía para el mismo.

\section{Ruderico Salazar Alzate}

\section{"Rodrigo Saldarriaga: un hombre del Renacimiento"}

1. En una ciudad como Medellín sin ninguna tradición teatral podríamos decir que Rodrigo se convirtió en un pionero del teatro, por un lado, por su gestión cultural y, por otro lado, como director de teatro y actor. 
Para mí en lo personal me legó de alguna manera su método riguroso de trabajo como director en donde era un ser integral en todas las disciplinas artísticas.

2. Son muchos los aportes del Maestro Rodrigo al teatro. Pero uno de los grandes legados fue el teatro de texto y contenido, tanto en el teatro universal escrito como en su dramaturgia. Para él todo comienza en el texto y la buena interpretación del mismo y la forma correcta de generar los contenidos a partir de la palabra y el buen trato a esta.

Son invaluables los aportes al teatro en verso y a todos los sistemas de estudio métrico que hizo en su dirección magistral.

3. Respetando mucho me identifico con Rodrigo cuando decía que había proliferado un teatro sin contenido ni técnica. Esto lo decía precisamente porque muchas propuestas teatrales solo tenían como objeto "Descrestar a los amigos" y quedarnos solo en lo que él llamó "El público privado".

Nuestro proyecto Pequeño Teatro ha creado no solo un proyecto artístico sino social de gran impacto como lo soñó el Maestro Rodrigo al que siempre llamé "Un hombre del Renacimiento".

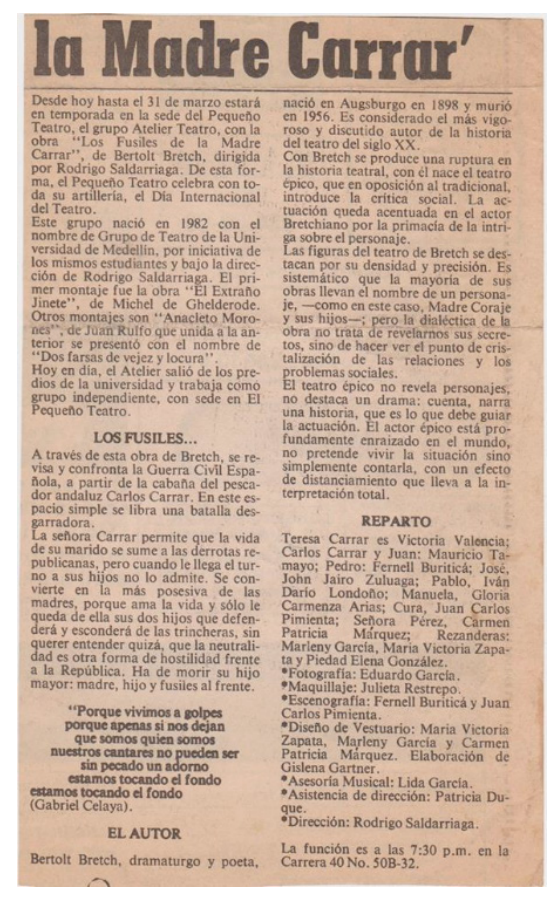

Fragmento de un periódico donde se informa sobre la representación de Los fusiles de la Madre Carrar de Bertolt Brecht por parte del Grupo de Teatro de la Universidad de Medellín. 


\section{Sandra Zea}

En mi opinión la obra de Rodrigo fue muy amplia. Realizó dramaturgias, direcciones escénicas y un proyecto de proyección teatral hacia la ciudad de grandes dimensiones con su "entrada libre con su aporte voluntario" en Pequeño Teatro

De lo que más conozco es de este último proyecto, del que fui testigo los últimos tres años de su vida. Tuve la fortuna de ver su florecimiento, la cantidad de público que acogía y la importancia que para este público era poder asistir a teatro, en Pequeño Teatro, en esas condiciones.

También tuve la fortuna de asistir a varias charlas en las él que sustentaba, en mi opinión con mucho acierto, este proyecto.

Desde ese momento y luego de mucha reflexión, estoy convencida de su pertinencia. En un mundo ideal, que se puede construir, ya lo demostró él, el teatro lo debe ver quien lo quiera ver, no importando si tiene o no dinero. El dinero para que este suceda lo debemos aportar todos, cada uno en la medida en que cada uno pueda. Aportar grandemente en generar el deseo del teatro en la gente de Medellín (en una sociedad como la nuestra en el que el arte es un accesorio innecesario) creo que fue su obra más importante, y en mí ha generado un profundo impacto.

\section{George Mario Ángel Quintero}

1. Mi experiencia de la propuesta teatral de Rodrigo Saldarriaga fue de un teatro altamente convencional, con rasgos parecidos a mucho del teatro de repertorio en el mundo. Siento que hubo un esfuerzo, más notable en los años recientes, de mantener un nivel de actuación, dirección, y puesta en escena, y que este esfuerzo tuvo su respuesta en un público fiel que encontró en el teatro que él y sus colaboradores producían un entretenimiento ameno que logró abrir un campo en la cotidianidad de un grupo significativo de habitantes de la ciudad.

En lo que se refiere a su dramaturgia, solo conozco tres obras que Rodrigo Saldarriaga haya escrito. Esas tres me dan la impresión de un dramaturgo que seguía creciendo. Cada una de estas obras (Cenizas en la cara, El Ejército de los Guerreros, y Los Chorros de Tapartó) representa un paso del dramaturgo hacia unas situaciones y un lenguaje más natural y propio. De las tres obras, Los Chorros de Tapartó es la que quizá más posibilidad tiene de quedar en el canon de dramaturgia hispanoamericana. Aunque es la más personal y vituperante de sus obras, su misma intimidad la hace más universal que las otras que son clásica e histórica, respectivamente. 
2. Considero que aunque su teatro fue convencional, representa un gesto de alejamiento del teatro explícitamente político de la generación anterior. Lo interesante de su generación es que todos eran políticamente comprometidos al nivel personal; sin embargo, decidieron buscar un teatro más universal que podría expresar sus preocupaciones de una manera lírica y estética. No siento que esta decisión se haya tomado como un abandono de convicciones o porque eran de alguna manera más artistas que los anteriores, para nada. Siento que este cambio surgió de un sentido común y un pragmatismo acerca de cómo mejor servir sus ideales y mantener una conexión fuerte con el pueblo.

Ahí es donde radico lo que es, para mí, la mayor contribución de Rodrigo Saldarriaga como hombre de teatro. Saldarriaga fue sobresaliente en crear en la ciudad de Medellín la alternativa de una vida en el teatro como algo viable y real. Todo lo que hace después de cierto momento con el Pequeño Teatro lleva a fortalecer la continuidad del arte. El enfoque en una producción continua, encontrar colaboradores que buscaban cada vez más responsabilidad, la estrategia del aporte voluntario, crear escuela, incitar a otros para que dirijan y monten obras, todos son parte de un esfuerzo general para que el teatro viva en la ciudad. De todos los que se han ido de nuestro escenario teatral, Rodrigo Saldarriaga ha sido el que mejor ha dejado la escena preparada para el segundo acto. Hoy el Pequeño Teatro es un colectivo de gente creativa que sabe trabajar junta para mantener vigente el proyecto $\mathrm{y}$ su quehacer creativo.

3. El verdadero ser de teatro es alguien cuyo aliento es incansable. Por encima de todo, esta persona tiene que proteger la sobrevivencia del proyecto, sea una sala, una compañía, o unas obras en repertorio. Para lograr este objetivo, hay que hacer lo que sea, desde presentar una obra en condiciones menos que óptimas hasta incluir obras en cartelera para asegurar un ingreso mínimo. Estas son realidades de sobrevivir en el tiempo. Rodrigo Saldarriaga, como buen hombre de teatro, entendía esta condición perfectamente y hacía todo lo necesario para que cada noche subiera el telón. Mi búsqueda en el teatro ha sido mucho más efímera y marcada por caprichos personales, y esto ha llevado a que la historia de nuestro grupo, Párpado Teatro, fuera un fiasco en términos de finanzas y de infraestructura. Cada cual encuentra su libertad como pueda, y me he encontrado contra la pared sin opciones muchas veces. La libertad que sí he encontrado es la de explorar un teatro que trata de elaborar una nueva convención con cada obra. Sería el primero en admitir que esto ha causado malentendidos con el público y con mis colegas. El riesgo es que ese malentendido se vuelva indiferencia. Rodrigo Saldarriaga, en cambio, logró aclarar una promesa que le hacía a su público, y eso permite que esa promesa se cumpla de nuevo con cada función. 


\section{Gustavo Adolfo Montoya Sánchez}

1. El hombre de gabán negro en ocasiones, barba de vikingo, melena rubia y alma húmeda de puro teatro, lo conocí en los albores de mi juventud cuando me iniciaba en las aventuras quijotescas del teatro. Una delicia inconmensurable era su imagen de molino de viento hecho hombre noble, capitán corajudo, político cristalino, trazado con líneas de arquitectura faraónica, con una voz de trueno que resonaba tanto en las tablas como en el diario vivir, de pasión volcánica, intuición sagaz y voluntad como el sílex; eso que el emanaba me incentivó a habitar los escenarios, no solo como expectante sino también como actor.

Un hombre que en su estado material está ausente, y que caló hondo y de forma centelleante en mi alma, en ese plano inmaterial de cada ser. Este guayacán florecido, inteligente, inamovible, que dejó un legado que no olvidaré.

El hombre de ojos verde y café, llevaba en la planta de sus pies incrustaciones de oro y cuarzo, con la palabra TEATRO, lo que determinaba ser un vikingo noble, poseedor de un gran barco teatral abierto al mundo. Fue tal mi suerte como aprendiz de este oficio, como un soñador de estos mundos posibles, que él era el arquetipo que quería encarnar, pero yo estaba en la otra orilla, sin perderlo de vista, dando mis primeros pasos en otra compañía teatral que florecía al otro lado del Pequeño Teatro, cruzando la avenida de La Playa. Crecí entonces en una época gloriosa de teatro, lejos de rapiñas burocráticas, porque el alma de estos artistas del mundo era intransferible, únicos en su generación.

Ese navío con Rodrigo Saldarriaga tiene en su haber el teatro del mundo, a través de Eurípides, Sartre, Moliere, Oscar Wilde, Esquilo, Shakespeare, Jorge Isaac, Tomas Carrasquilla, Bertolt Brecht, Strindberg, entre otros; una lista prolífica para un Medellín y un país sin memoria, que poco conoce la condición humana desde su propio drama cotidiano, mucho menos desde autores universales que han cavilado hondamente sobre la muerte, sobre esa dicotomía que se despliega diariamente en el devenir humano; solo estas incrustaciones en oro y cuarzo pueden hacer esto, tener un teatro que le da la vuelta al mundo en menos de ochenta días, un Julio Verne contemporáneo, un guayacán florecido, impoluto.

Finalmente, recuerdo tu alma húmeda de teatro, esa presencia en una noche cuando, en tu nombre, yo representaba Porfirio Barba Jacob "El hombre que parecía un caballo", supe del amor que le tenías a este autor, allí, en ese estado de locura y muerte vi venir tus ojos verde y café sobre mis ojos, cerrando el telón de mis párpados para decirme "gracias, poeta, en qué 
quedamos", momento en que tomaron sentido aquellas palabras de Enrique Buenaventura: "la vida no se puede ensayar y el teatro es el modo de ensayar la vida".

2. Esta camada de hombres y mujeres de la década de los 70 y 80 son para mí únicos en su especie, tocaron el cielo teatral para siempre sin tocar aro, tenían un arco iris del que se desplegaban sus luces teatrales que nunca se apagaron. Son pocos los que quedan, pero, "a Dios gracias", esos pocos son crisoles del movimiento teatral medellinense, y Rodrigo Saldarriaga hace parte de esa gesta indómita que propuso y fortaleció el teatro, que mostró que las tablas podrían ser su mejor lecho de muerte, que su visión fue una alquimia de ideas realizables, dejó un navío teatral capaz de acoger a más de seiscientos espectadores, una biblioteca, una casa con dos salas para el rito y un repertorio teatral con más de setenta obras de teatro, es decir, un abanico extraterrenal, y qué decir del sinfín de hombres y mujeres que han pisado las tablas de su legado material e inmaterial, que se impregnaron y, a su vez, siguen impregnando de los aromas teatrales que sedujeron a las generaciones anteriores.

En este orden de ideas, en esa esquina se condensa un patrimonio importantísimo para la cultura de la ciudad, un lugar que abre las puertas a las diferentes formas y estilos que confluyen en el mundo teatral de la ciudad. Una casa con dos salas de teatro poseídas, embrujadas, hechizadas, con cientos de autores, de poetas, de dramaturgos, de directores y actores que han pulsado hasta la última gota de sangre en las tablas, que han proyectado un efecto catártico en una población, una ciudad indolente y silente.

3. Ese disfrute consistía en dar cuenta de un hombre que era sauce, roble, nazareno, madera pura para el teatro; un faro alto e inagotable en su luz. ¿Cuánto teatro transitó por su sangre que hoy se ha convertido en un referente histórico y estético para el teatro? Esa adhesión consistía en escucharlo, ya que su mirada era horizontal con el teatro, era un contendor de gran quilate para abordar dramaturgos contemporáneos y clásicos, no sobra decir que cada navío tiene su capitán, así como cada árbol tiene su savia, su esencia particular. En el lienzo vacío tenía la eficacia simbólica y dramatúrgica que pulsaba con los latidos de estos tiempos tan caóticos; así es el Pequeño Teatro, que de pequeño no tiene nada, porque ellos están en un convencimiento de su oficio o de su quehacer teatral, fieles al maestro como la más grande heredad que lleva más de treinta y cinco años de existencia y que seguirá cuantificándose a la sombra de ese guayacán florecido en obras para esta Medellín pacata, que tanto enorgullece a las muchas almas extraviadas que convergen en este valle provincial. Gracias, Rodrigo, por tu legado. 


\section{Olga Vásquez}

1. Rodrigo Saldarriaga fue un promotor del teatro, abrió un espacio para la ciudad, que luego democratizó con su política de aporte voluntario, para que todos pudieran asistir y disfrutar en un espectáculo. Generó otros espacios como escuela de formación para incentivar la profesionalización del sector y estos fueron sin duda, grandes aportes al movimiento teatral en Medellín y en Colombia.

2. Rodrigo fue el pionero del Teatro Moderno en Antioquia. Fue el primero en Medellín que generó, sin importar las condiciones, una temporada permanente de funciones semanales para que el público empezara a considerar el hábito de ir a teatro y a partir de eso, se empieza a considerar el consumo cultural de Medellín. Otros grupos lo tomaron como referencia, tanto para seguir sus posturas estéticas y de gestión como para contradecirlas y ampliar el panorama del contexto teatral en la ciudad.

3. El Pequeño Teatro fue uno de los primeros en el país que montó grandes clásicos de la dramaturgia, inspirado en el Teatro Libre de Bogotá, que tenía trayectoria en este campo. Entonces sus propuestas iban enfocadas a abordar la cultura general teatral, por decirlo de alguna manera y traer estas propuestas de reconocimiento mundial, a una ciudad que poco conoce, sobre el tema.

Su estética es muy particular, muy shakesperiana, a veces puede parecer un poco compleja y difícil de comprender, porque muchos espectadores no conocen de clásicos y no lo sienten cercano.

\section{Omaira Rodríguez}

1. Fue siempre una enseñanza nueva y profunda en mi vida, ya que él fue él quien me enseño desde muy pequeña a mirar el mundo a desde el arte en todas sus manifestaciones, tanto en lo teatral como en todas las otras cosas, pintura, escritura, lectura etc. Él nos enseñó a mirar un mundo abierto al conocimiento en todas sus manifestaciones.

2. Él hizo del teatro lo que quiso en su vida. Por ser un gran humanista y un gran artista nos dejó el legado más grande que pueda tener un grupo y una ciudad, un espacio para seguir manifestándonos con el arte. En nosotros queda ese sello que nos caracteriza: hacer obras que amemos y que digan cosas para la reflexión en todas sus latitudes, y lo más grande, que el arte que hagamos sea siempre un encuentro con la gran sabiduría de la vida, que no nos quedemos callados ante lo malo de este mundo. 
3. Lo estético en el arte es muy relativo porque tiene que ver con cada individuo, cada cual ve la vida como quiera y, por ende, la interpreta como quiera y como es en cada uno, así es el arte, cada persona que se considere artista tiene su sello y lo hace como quiera manifestarse dentro de su propuesta. "Rodri" hizo la suya y yo personalmente me alegro de poder estar con él para hacer la mía, que aunque no son la misma me entregó un camino para emprender mi viaje como artista, un artista no se repite, pero sí recoge de los mejores para su cultivo. Y a mí me tocó el mejor.

\section{BenHur Carmona}

El nombre de Rodrigo Saldarriaga resuena dentro de mí, como un cohete de luz... Hoy he sentido gravitar su sombra frente a mi tablero de ajedrez, solo una vez jugamos una partida y quedamos en "tablas" -la suerte estaba de mi parte-, y acordamos jugar otro día, pero sin querer fue esa una "final de partida".

Tiene el escenario, a diferencia de la vida, la certeza de las acciones -me contaba Rodrigo- La incertidumbre es derrotada por las estructuras rígidas de la actuación: sabemos exactamente en dónde estamos y qué estamos haciendo en cada instante; sabemos de la velocidad y de la localización de la partícula. Tenemos los actores el dominio de la vida de los personajes: tenemos el tono, tenemos el tiempo y también el tempo; el color, la temperatura, el volumen; tenemos el ethos y también tenemos las dimensiones psicológicas en nuestro cuerpo. Sabemos el instante de la muerte de nuestro personaje...

Entonces estábamos en la casa-lote de Villa Hermosa, la primera sede de Pequeño Teatro. Jugábamos en un intervalo sobre preparativos para montaje de Macbeth.

Cuando llegué a Pequeño Teatro, invitado gracias a la cortesía de José Gabriel Mesa, mi profesor de Literatura -entonces cursaba yo los estudios de secundaria- era un jueves o viernes a esa hora elemental del día después de las clases de colegio; entrando a Pequeño Teatro -apenas podía creer que pudiera estar (no en Pequeño Teatro) sino dentro de pequeño teatro-, me pareció ver el escenario análogo a un rectángulo que sobresalía de la circunferencia de la construcción e invadía el sector del proscenio; medía aproximadamente 13 metros de ancho por 8 metros de profundidad y un metro y medio de altura. Los artificios y el candor del hombre de teatro no tienen fin: hambre, sed, amargura, sueño, guerra, muerte y los otros hábitos humanos, en Pequeño Teatro, no existían al principio del tiempo.

Libre ahora de esperanza y miedo vuelvo a mirar los arduos borradores de mi memoria cuando buscaba lo soñado y sin saber de teatro menos que de la nada, 
era dueño de mi entusiasmo atravesando el fondo de algún sueño por el cual ya caminaban Shakespeare o Moliere. Ese tiempo ya no es la mera sucesión cuantitativa, el pasar de los minutos, horas, días, semanas y meses, sino el instante que no transcurre, no es el tiempo cronológico sino la conciencia de la duración.

Era tenaz. Pero ¿qué sucede cuando escucho a Rodrigo por primera vez hablar de teatro? Rodrigo, un hombre trabajado por el teatro. Un hombre que ni siquiera esperaba la muerte. Las pruebas de la muerte son estadísticas y nadie hay que no corra el albur de ser el primer inmortal, diría Borges, pero nosotros hablando de Shakespeare éramos inmortales.

Borges no lo entendería, como yo no entendí una sola palabra de Rodrigo aquella tarde. Todos estábamos en silencio escuchando; Rodrigo tenía la virtud de hablar una hora, dos horas, tres horas continuadas sobre teatro; entre más desplegaba sus contenidos menos entendía yo, al final del día sentí que las palabras sobre teatro no eran más que laberintos, no había una puerta, estaba dentro de Pequeño Teatro, un laberinto que no poseía para mí anverso ni reverso, menos externo muro ni secreto centro.

Así fue el primer encuentro con Rodrigo Saldarriaga \& Pequeño Teatro. Extraordinario, es decir, fuera de lo ordinario.

Al día siguiente pudiera volver o desaparecer, como se quiera se trataba de una invitación sin compromiso de las partes.

¿Y ahora? me preguntaba.

Al día siguiente después de las clases del colegio, estaba impaciente por volver a Pequeño Teatro.

Inexorables los días, meses \& años que pasaron para leer libros nuevos que me prestaba Rodrigo, entonces sí que había ambiente teatral para enseñarme a leer y escribir; sentía, en el pecho y en el corazón de cada actor, y sobre todo de Rodrigo que el deseo para hacer teatro era tan apremiante y de tanto estoicismo como saciar la sed o matar el hambre.

Entonces comenzaron las primeras grandes puestas en escena, obras monumentales que aspiraban a fijar por siglos las angustias del país, sus problemas y esperanzas. Sentíamos la confidencia en el teatro, y en el teatro de calidad perenne.

Rodrigo recién había llegado de su primer viaje a Europa, después de presenciar en Londres -Royal Shakespeare Company con directores como Peter Brook, Peter Hall, Trevor Nunn y en París, de Ionesco "La cantante calva" y Monsieur Comedie, de Italia el Piccolo Teatro de Milan con "Arlequino Servidor de dos 
Señores" de Carlos Goldoni- puesta en escena de Giorgio Strelher, entre otras luminarias del teatro en Europa.

En todo caso, para Rodrigo en su vocabulario siempre dos palabras fundamentales: "Pequeño Teatro" era la medida de las cosas, quiso y a veces creyó saberlo todo, expresarlo todo, transformarlo todo, amar el teatro y consumirse en la llama, y agotar la pasión, desdeñar los límites y luego sobrevivir o salvarse. Como nos cuenta el mismo Rodrigo en su libro Tercer timbre, después de sobrevivir a un pre-infarto: "[Me] Reviven en la memoria al ritmo, ahora lento pero firme del corazón todos mis fantasmas, todos mis muertos, que ya son muchos, que ya son todos: los del teatro, los actores y los personajes; los de la vida, mis amigos y mi familia, y los otros que también son fantasmas. Las quinientas butacas de Pequeño Teatro se van llenando de figuras lívidas que sonríen o ríen a carcajadas burlándose de la ridícula escena interpretada por el más vanidoso y petulante de los actores, yo."

En el fondo de todas sus obras y fundaciones, Rodrigo se debatía en un antiguo espíritu existencial. Esa es la clave para leer y acaso entender a Rodrigo Saldarriaga. La tarea es compleja porque en su existencialismo participan corrientes muy diversas y a veces encontradas.

Alma ahora silenciosa que resucita entre nosotros con vigencia nunca agotada. A pesar de su leyenda... no amaba el desorden ni la bohemia; era, por el contrario, un espíritu ordenado, puntual, exacto, devorado por ese afán de exactitud, se presentaba siempre a los ensayos con sobrada anticipación. Era una manera de escaparnos de temporadas de locura, de alegría o de infierno; Rodrigo como todos los hombres de teatro era un campo de batalla. Vivía en paz con los hombres y en guerra con sus entrañas.

Su pensamiento fue siempre original, como diría Simone Weil, los pensamientos que se relacionan con la espiritualidad del trabajo -o lo presienten- y que están dispersos en la obra de Rousseau, Sand, Tolstoi, Marx, Proudhon, son los únicos pensamientos originales de nuestra época, los únicos que no hemos tomado de los griegos.

Mi relación con Rodrigo Saldarriaga y Pequeño Teatro comenzó con Shakespeare sobre el montaje de Macbeth; los ensayos permanentes -después de mis clases de colegio- los talleres de carpintería, vestuario y zapatería convirtieron la sede en un "pandemónium teatral" como decía Rodrigo, hasta el punto de obligarnos a construir un galpón en el lote contiguo para poder armar una escenografía de dos toneladas y realizar los ensayos generales de Macbeth. Para el montaje, en primer lugar, del galpón de 144 metros cuadrados de área y seis metros de altura nos cambiaron las herramientas de carpintería por las de 
albañilería y en menos de una semana teníamos el primer espacio construido para hacer teatro. Allí realizamos el pre-estreno de la obra para los amigos más allegados.

Con Macbeth y otra de las obras "Los intereses creados" salimos a recorrer todo el país. Primero hacia el norte sin ruta definida. Recuerdo que la primera función de la obra de Shakespeare la hicimos en Caucasia en un viejo teatro de cine, a las once de la mañana, además del calor incesante sobre nuestro vestuario de pieles, sin contar las pelucas, nuestros parlamentos competían con los vallenatos saliendo de las rocolas del vecindario, entonces cuando llegaba el Rey Duncan de visita al castillo de Macbeth la música de fondo era vallenato de puro carnaval, pero esto no fue suficiente como para sentirnos heridos en el amor propio como consagrados actores de Shakespeare presentando en Caucasia; el golpe certero fue cuando esa misma mañana el escenario colapsó a causa de las dos toneladas de escenografía usadas en Macbeth, palabras más palabras menos, terminamos armando partes de la escenografía y presentando solo algunas escenas.

Otras presentaciones, en cambio, más adelante en los pueblos del sur de Córdoba estuvieron de locura, en Planeta Rica por ejemplo, por primera vez y última vez en la vida se revendieron boletas para nuestra presentación.

Cada vez que regresaba de Nueva York a Medellín visitaba en las mañanas a Rodrigo en su oficina de Pequeño Teatro, ahora en la sede de la calle Córdoba, en las mañanas, digo, porque las tardes continuaban siendo reservadas para los ensayos.

Nos alegrábamos del re-encuentro y suspendía generosamente lo que estuviese haciendo sobre todo escribiendo en sus libretas o diseñando puestas en escena; entonces tomábamos tinto y hablábamos de sueños y esperanzas... tal vez presentía en su mirada una tristeza, pues los hombres atormentados por una tristeza profunda se traicionan cuando son felices, tienen un modo de aferrarse a la felicidad, como si quisieran estrujarla y sofocarla entre sus brazos en un arrebato de celos.

Fue la última vez que nos vimos. 